Document downloaded from:

http://hdl.handle.net/10251/51249

This paper must be cited as:

Silva, C.; Luz, G.; Gamboa Martínez, TC.; Mano, JF.; Gómez Ribelles, JL.; Gómez Tejedor, JA. (2014). Poly(epsilon-caprolactone) electrospun scaffolds filled with nanoparticles. Production and optimization according to Taguchi's methodology. Journal of Macromolecular Science Part B Physics. 53(5):781-799.

doi:10.1080/00222348.2013.861304.

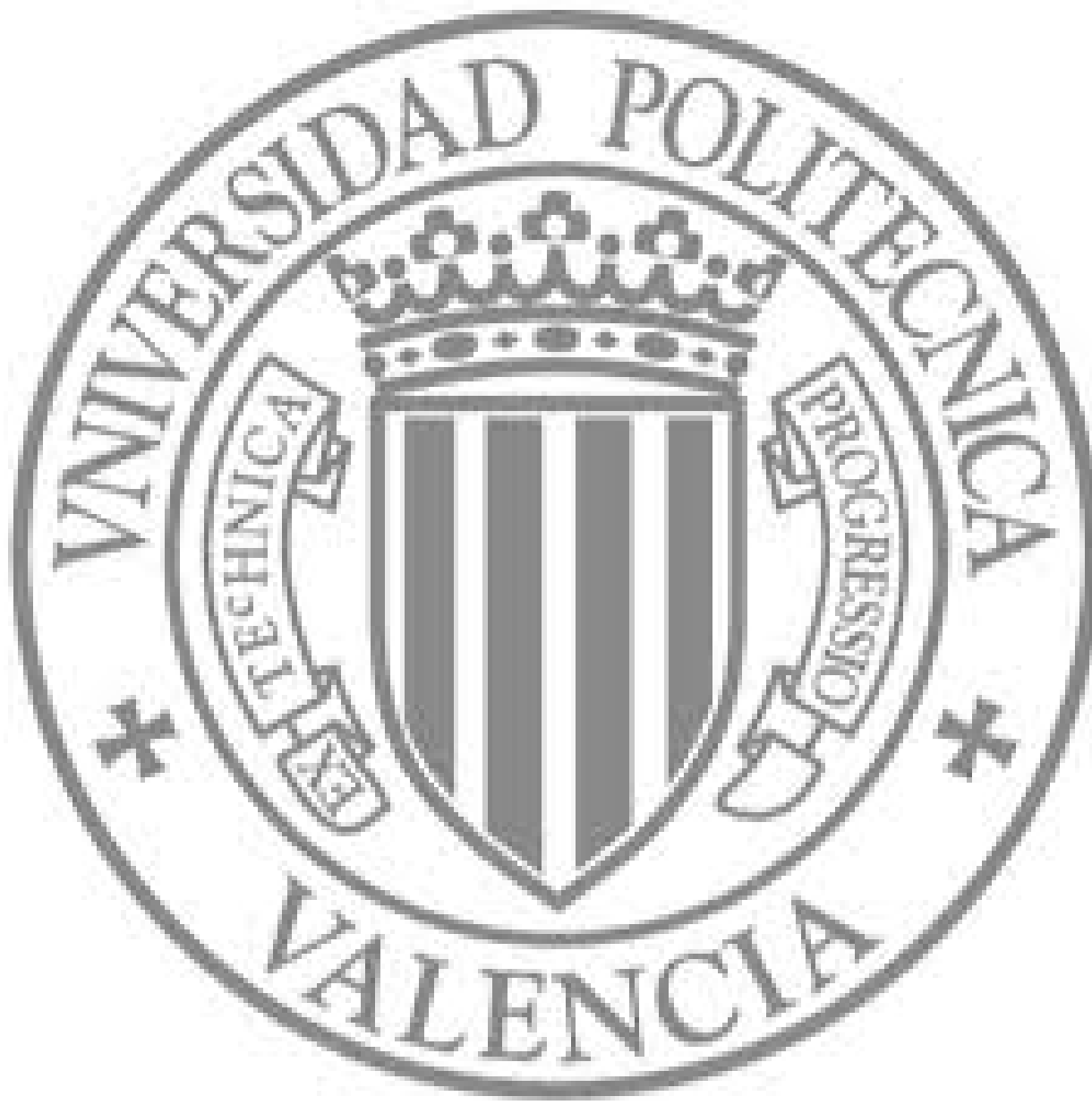

The final publication is available at

http://dx.doi.org/10.1080/00222348.2013.861304

Copyright Taylor \& Francis 


\title{
Poly( $\varepsilon$-caprolactone) electrospun scaffolds filled with nanoparticles. Production and optimization according to Taguchi's methodology
}

\section{Journal of Macromolecular Science, Part B: Physics. 53 (5), 2014 781-799 \\ CSR Silva $^{1, \mathrm{a}}$, GM Luz $^{2,3, \mathrm{~b}}$, TC Gamboa-Martínez ${ }^{1, \mathrm{c}}, \mathbf{J F}$ Mano $^{2,3, \mathrm{~d}}, \mathbf{J L}$ Gómez Ribelles $^{1,4, \mathrm{e}}$ and JA Gómez-Tejedor ${ }^{1 *}$}

\section{Running Title: PCL electrospun scaffolds with nanoparticles}

${ }^{1}$ Center for Biomaterials and Tissue Engineering, Universitat Politècnica de València, Camino de Vera s/n, 46022 Valencia, Spain.

23B's Research Group - Biomaterials, Biodegradables and Biomimetics, University of Minho, Headquarters of the European Institute of Excellence on Tissue Engineering and Regenerative Medicine, AvePark, 4806-909 Taipas, Guimarães, Portugal

${ }^{3}$ ICVS/3B's - PT Government Associate Laboratory, Braga/Guimarães, Portugal

${ }^{4}$ Networking Research Center on Bioengineering, Biomaterials and Nanomedicine(CIBER-BBN), Valencia, Spain

E-mails: $\quad$ axbf3fflhruyz@hotmail.com, $\quad$ bisela.luz@ dep.uminho.pt ctagammar@doctor.upv.es, ${ }^{d}$ jmano@dep.uminho.pt, ${ }^{\mathrm{e}}$ jlgomez@ter.upv.es

*E-mail for correspondence: jogomez@ fis.upv.es

\begin{abstract}
Polycaprolactone scaffolds were produced by electrospinning. Polymeric solutions in a mix of dichloromethane and dimethylformamide were electrospun to form fibers in the sub-micron range. Physical properties of the polycaprolactone solutions were characterized with respect to density, viscosity, conductivity and surface tension. Processing was optimized following Taguchi's methodology to select the set of processing parameters that resulted in producing fibers with the smallest diameters, minimum number of defects and with the narrowest distribution of fiber diameter. Morphology of electrospun fibers was qualitatively and quantitatively analyzed for the different sets of processing parameters. The optimum conditions found to electrospun polycaprolactone were used to process polycaprolactone solutions containing nano-particles of hydroxyapatite or bioactive glass. Bioactivity of nano-composite electrospun membranes in simulated body fluid was analyzed and biological response was tested by assessing proliferation and viability of MT3C3-E1 preosteoblasts cultured on polycaprolactone and its nanocomposite membranes.
\end{abstract}




\section{Introduction}

In the last several years the application in tissue engineering of membranes or threedimensional structures made of aligned or randomly oriented nanofibers has been extensively studied. These materials act as supports for cell expansion or differentiation or as a vehicle for cell transplant to the damaged tissue or organ. In particular, nanofibrillar structures have proven to be suitable for bone regeneration. It has been shown that nanofiber membranes sustain attachment and proliferation of bone marrow mesenchymal stem cells (MSCs) [1-6], and enhance osteogenic differentiation. Much of this research has been performed using biodegradable polyesters, in particular polycaprolactone[3, 7-9].

Polycaprolactone, PCL, is a linear, resorbable, aliphatic polyester with physical properties that make it quite interesting to use to produce tissue engineering scaffolds, such as non-toxicity, non-immunogenicity, good solubility, low melting point $\left(59-64{ }^{\circ} \mathrm{C}\right)$, good mechanical properties (modulus and elasticity), exceptional blend-compatibility and it is slowly biodegraded by hydrolysis [10-16]. In fact, the use of PCL to support attachment and proliferation of different types of cells has been explored [11, 17-19].Although exhibiting good properties for these applications, PCL alone is not bioactive and its stiffness is much less than that of bone tissue; the incorporation of ceramics such as hydroxyapatite (HA) and bioactive glass (BG) tends to help both requirements. [9, 11, 12, 18-21]

Hydroxyapatite is a type of calcium phosphate with chemical composition, $\mathrm{Ca}_{10}\left(\mathrm{PO}_{4}\right)_{6}(\mathrm{OH})_{2}$, structure and size resembling the mineral component of bone. Due to its good properties, such as bone mineral-like features, bioactivity, biocompatibility, non-toxicity, non-inflammatory, non-immunogenic, osteoinducer, osteoconducter, relatively stable degradation and mechanical strength, this bioceramic has gained increasing attention for bone tissue repairing applications [20, 22-29]. Bioactive glasses, having bone bonding ability due to their surface reactivity, excellent osteoconductivity, and controlled biodegradability, are commonly applied in bone tissue engineering. The classic bioglass composition, containing $\mathrm{SiO}_{2}, \mathrm{Na}_{2} \mathrm{O}, \mathrm{CaO}$ and $\mathrm{P}_{2} \mathrm{O}_{5}$ (wt\% $45-24.5-24.5-6$ ), was approved by the U.S. Food and Drug Administration (FDA) while other compositions might contain sodium or other elements, such as magnesium or potassium, among others [20, 21, 30,31]. When used in the form of nano-particles, both ceramics present improved properties with respect to protein adsorption and cell adhesion due to the small size and high specific surface area [21, 27-30, 32, 33].

Composite nanofiber mats have been produced combining PCL and hydroxyapatite nanoparticles, or inducing apatite precipitation from simulated body fluids [1, 8, 9, 33-36]. The aim of this work was to analyze, in detail, the electrospinning process to produce PCL and PCL / hydroxyapatite or bioactive glass nanocomposites nanofibrilar scaffolds.

The electrospinning process typically has a setup consisting of a capillary through which the polymer solution or melt is forced by a syringe pump or gravity action, a direct current high voltage source and a grounded collector [37]. An electric field (up to $30 \mathrm{kV}$ ) is created between the polymer solution drop at the end of the tip and the collector. This electric field provokes the projection and acceleration of a fiber jet towards the grounded collector. The evaporation of the solvent while the solutions travel from the tip to the collector produces solid polymer fibers [17, 37-39]. Some instability of the jet is inherent to the electrospinning process $[38,40]$. Bending instabilities affect the diameter and development of the polymer jet and are responsible for possible defects such as branching, bead formation and drops, depending on the governing parameters [38-40]. The governing parameters include solution properties (concentration, viscosity, etc), process (gap distance between tip and collector, flow 
rate, etc) and ambient parameters (temperature and humidity); their control and adjustment allows the production of suitable fibers [41-44].

According to the literature the most considered governing parameters are solvents ratio, when the polymer is dissolved in mixture of solvents, polymer concentration in the solution, polymer molecular weight, applied voltage, solution flow rate, and nozzle to collector distance $[39,42,45,46]$. Thus, the distribution of fiber diameters and mean values strongly depend on a quite high number of parameters, which makes it very difficult to understand the influence of each parameter on membrane microstructure and to optimize the process with respect to specific objectives, such as obtaining narrow fiber size distributions or specific mean diameters. Taguchi's methodology is commonly used for industrial process optimization and has also been applied in the optimization of the electrospinning technique. With this method, the number of experiments is reduced by performing orthogonal arrays with beneficial factors combination and reliable quality control [42, 44, 46-52].

\section{Materials and methods}

\subsection{Materials}

Poly( $\varepsilon$-caprolactone) (PCL) from Polysciences Europe GmbH (Germany) with an average molecular weight $\left(M_{w}\right)$ of 43,000-50,000 Da in the form of pellets was used. Dichloromethane (DCM, 99.8\% purity, synthesis grade) and dimethylformamide (DMF, 99.8\% purity) were obtained from by Scharlau Chemie, S.A. (Spain). Hydroxyapatite nanoparticles (HA-NP, with particle size smaller than $200 \mathrm{~nm}$, and a purity level higher than 97\%) were delivered by Sigma-Aldrich (Spain). Bioactive glass nanoparticles (BG-NP) with the composition $\mathrm{SiO}_{2}: \mathrm{CaO}: \mathrm{P}_{2} \mathrm{O}_{5} \quad(55: 40: 5 \mathrm{~mol} . \%)$ were prepared. Spherical-shaped nano-particles were obtained with sizes ranging from $100 \mathrm{~nm}$ to $800 \mathrm{~nm}$. The BG-NPs were produced using a solgel methodology, as described elsewhere [53, 54].

Dulbecco's Phosphate Buffered Saline (DPBS), ascorbic acid, formalin and glutaraldehyde were purchased from Sigma Aldrich (Spain). Trypsin-ethylenediaminetetraacetic acid (EDTA), penicillin/streptomycin (P/S), fetal bovine serum (FBS) and sodium pyruvate were obtained from Fisher (Spain). DL-Glutamine was purchased from Lonza (Spain) and 3-(4,5 dimetiltiazol-2-il)-5-(3-carboximetoxifenil)-2-(4-sulfofenil)-2H-tetrazolium inner salt (MTS) from Promega (Spain). Monoclonal antivinculin and $\alpha 5$ integrin antibodies, produced in mice, were purchased from Sigma Aldrich (Spain) and Immunotech (UK) respectively; BODIPY® FL phallacidin and Alexa Fluor ${ }^{\circledR} 633$ from Life Technologies (Spain). VECTASHIELD ${ }^{\circledR}$ mounting media with incorporated 4',6-diamidino-2-phenylindole (DAPI) was from Vector Laboratories (UK). All the chemicals were used as-received, without further purification.

\subsection{Solutions preparation}

Several PCL solutions were prepared by stirring in mixtures of DMF and DCM with different ratios. After a preliminary analysis the solution concentration values 10, 12 and $15 \% \mathrm{w} / \mathrm{v}$ and the solvents ratios of $80 / 20$ and $90 / 10$ (DCM/DMF) by volume were selected for the optimization process. Homogeneous solutions were obtained after one hour stirring at room temperature.

Nano-particles were incorporated and dispersed in the polymer solution under ultrasonic stirring (Bandelin UW 2200, Germany), for 5 - 10 minutes. In order to avoid overheating, ultrasound was applied in sequences of 2 seconds followed by another two seconds of rest, at a power of $40 \mathrm{~W}$. As the BG-NPs were larger sized, they needed more time to disperse. 
Electrospinning was performed immediately after dispersing the nano-particles in the PCL solution, in order to avoid nano-particles deposition on the bottom of the syringe.

\subsection{Electrospinning}

A syringe pump Multi Phaser ${ }^{\mathrm{TM}}$ NE - 1000 of New Era Pump System Inc. (USA), with a $10 \mathrm{~mL}$ syringe was connected to a hypodermic needle with $0,5 \mathrm{~mm}$ inner diameter (the same needle diameter was used in all the experiments), allowing control of the flow rate within the range of $0.3-0.5 \mathrm{~mL} / \mathrm{h}$. The needle was connected to a high voltage supply, Glassman High Voltage Inc. (USA) that allowed varying the voltage between 15 and $25 \mathrm{kV}$. A horizontal metallic collector, connected to ground, was situated at a distance between 10 and $20 \mathrm{~cm}$ under the needle. The solution concentrations varied between 10 and $15 \mathrm{wt} \%$.

\subsection{Taguchi 's orthogonal design}

The method in this case consisted of three main steps; a first step consisting of the parameter selection defining the levels of variation of each of them; a second part consisting of the array selection and the performance of the experiments and finally a third part which concluded the analysis process by determining which were the most influential parameters on average fiber diameter and fiber diameter distribution width and the values of the set that allows obtaining the optimum electrospun mat that, in this work, was defined as that with the smallest diameter fibers and most homogeneously distributed fiber diameter and with no apparent defects such as beads or drops.

The number of factors that influence the electrospinning process is quite large; some of them are related to the characteristics of the polymer solutions, other with the process itself. Taguchi's design was performed on the basis of five selected parameters, two of them: solution concentration and solvents ratio were related to the polymer solution while three more: flow rate, travelling distance and applied voltage are characteristics of the electrospinning process. According to the literature these seemed to be the most relevant parameters for the experimental design concerning polycaprolactone electrospinning [13, 39, $42,45,46,55-58]$. Each parameter was varied at three levels, a minimum, a medium and a maximum, except for the solvents ratio where only two levels were taken into account. Given the number of design parameters, the orthogonal array $L_{18}$ should be used $[46,56,57]$ and so it was possible to evaluate parameter influence with only 18 experiments, which are shown in Table 1. 
Table 1: Design of orthogonal table $L_{18}$ and mean value $(\bar{x})$ and standard deviation $(\sigma)$ of the diameter of obtained fibres. And results for fiber diameter distribution for the nano-particles incorporation study.

\begin{tabular}{|c|c|c|c|c|c|c|c|}
\hline $\begin{array}{l}\text { Exp. } \\
\text { No. }\end{array}$ & $\begin{array}{c}\text { Solvents ratio } \\
(\mathrm{DCM}-\mathrm{DMF} \%)\end{array}$ & $\begin{array}{c}\text { Applied } \\
\text { voltage } \\
(\mathrm{kV})\end{array}$ & $\begin{array}{c}\text { Flow } \\
\text { rate } \\
(\mathrm{ml} / \mathrm{h}) \\
\end{array}$ & $\begin{array}{c}\text { Solution } \\
\text { concentration } \\
(\% \mathrm{w} / \mathrm{v})\end{array}$ & $\begin{array}{c}\text { Gap } \\
\text { distance } \\
(\mathrm{cm})\end{array}$ & $\bar{x}(\mu \mathrm{m})$ & $\sigma(\mu \mathrm{m})$ \\
\hline 1 & $90-10$ & 15 & 3 & 12 & 10 & 1.27 & 0.71 \\
\hline 2 & $90-10$ & 15 & 4 & 10 & 15 & 1.69 & 0.71 \\
\hline 3 & $90-10$ & 15 & 5 & 15 & 20 & 3.75 & 1.20 \\
\hline 4 & $90-10$ & 20 & 3 & 12 & 15 & 2.59 & 0.77 \\
\hline 5 & $90-10$ & 20 & 4 & 10 & 20 & 1.95 & 0.74 \\
\hline 6 & $90-10$ & 20 & 5 & 15 & 10 & 3.44 & 2.79 \\
\hline 7 & $90-10$ & 25 & 3 & 10 & 10 & 1.89 & 0.56 \\
\hline 8 & $90-10$ & 25 & 4 & 15 & 15 & 1.43 & 0.54 \\
\hline 9 & $90-10$ & 25 & 5 & 12 & 20 & 1.68 & 0.77 \\
\hline 10 & $80-20$ & 15 & 3 & 15 & 20 & 0.81 & 0.63 \\
\hline 11 & $80-20$ & 15 & 4 & 12 & 10 & 1.03 & 0.52 \\
\hline 12 & $80-20$ & 15 & 5 & 10 & 15 & 0.57 & 0.41 \\
\hline 13 & $80-20$ & 20 & 3 & 10 & 20 & 0.54 & 0.27 \\
\hline 14 & $80-20$ & 20 & 4 & 15 & 10 & 1.68 & 0.68 \\
\hline 15 & $80-20$ & 20 & 5 & 12 & 15 & 1.77 & 0.74 \\
\hline 16 & $80-20$ & 25 & 3 & 15 & 15 & 1.60 & 0.71 \\
\hline 17 & $80-20$ & 25 & 4 & 12 & 20 & 1.12 & 0.54 \\
\hline 18 & $80-20$ & 25 & 5 & 10 & 10 & 0.98 & 0.52 \\
\hline \multicolumn{8}{|c|}{ Percentage of nano-particles incorporated } \\
\hline \multicolumn{6}{|c|}{ HA-NP 1\% } & 0.49 & 0.24 \\
\hline \multicolumn{6}{|c|}{ HA-NP 5\% } & 0.35 & 0.10 \\
\hline \multicolumn{6}{|c|}{ HA-NP 10\% } & 0.29 & 0.11 \\
\hline \multicolumn{6}{|c|}{ BG-NP 1\% } & 0.61 & 0.30 \\
\hline \multicolumn{6}{|c|}{ BG-NP 5\% } & 0.57 & 0.29 \\
\hline \multicolumn{6}{|c|}{ BG-NP 10\% } & 0.50 & 0.24 \\
\hline
\end{tabular}

\subsection{Polymer solution characterization techniques}

The density of each solution was calculated by gravimetric methods. The conductivity of the polymer solutions was measured at room temperature using an EC - Meter BASIC $30^{+}$ conductivity meter with a Crison 5071 probe (Spain). A Proton Ubbelohde Viscometer n8035 size 2 ASTM D445*TP-71*ASTM D, suitable for transparent liquids, was used for viscosity measurement. An OCA20+ Contact Angle System from Dataphysics (Spain) was used to measure surface tension by the pendant drop method.

\subsection{Mats characterization by scanning electron microscopy}

The morphology of the electrospun mats was assessed using a JEOL JSM-5410 scanning electron microscope (Japan) with an acceleration voltage of $15 \mathrm{kV}$ and the resulting images were taken with magnifications between 350 and 10,000. Previous to the SEM analysis the sample surfaces were gold sputtered. 


\subsection{Bioactivity tests}

In-vitro bioactivity tests on the obtained nanocomposites were performed to check the potential osteoconductive properties of the materials. An acellular simulated body fluid (SBF) (1.0x) was prepared, with ions concentration nearly equal to human blood plasma. The SBF composition and preparation was previously described by Kokubo and co-workers [59]. The composite membranes were immersed for 7 days in the SBF and SEM was used to assess biomimetic apatite deposition onto the surfaces.

\subsection{Cell culture}

The electrospinning membranes were washed for two days with $70 \%$ ethanol to remove any remaining solvent; the ethanol was changed every four hours. Samples were then dried in vacuum for two days at room temperature until constant weight. Disks of $5 \mathrm{~mm}$ diameter were cut from the electrospun scaffold and sterilized by $25 \mathrm{kGy}$ gamma irradiation (Aragogamma Company, Spain) before cell culture.

The sterilized membranes were washed with DPBS, preconditioned in Dulbecco's Modified Eagle's Medium (DMEM) with $1 \mathrm{~g} / \mathrm{L}$ of D-glucose and incubated at $37^{\circ} \mathrm{C}$ and $5 \% \mathrm{CO}_{2}$ for $24 \mathrm{~h}$.

Mouse pre-osteoblastic cells (MC3T3-E1, obtained from the Riken Cell Bank, Japan) were used for cell culture. The cell suspension was diluted to obtain a final concentration of 780,000 cells $/ \mathrm{mL}$. Samples disks were placed in a 48 -well tissue culture plate and over each sample surface $10 \mu \mathrm{L}$ of the cell suspension was dropped and incubated for $1 \mathrm{~h}$ at $37^{\circ} \mathrm{C}$ and $5 \%$ $\mathrm{CO}_{2}$ for cell adherence. Afterwards, the culture medium (DMEM 1g/L D-Glucose, $10 \% \mathrm{FBS}$ and $1 \% \mathrm{P} / \mathrm{S}$ ) was added and the samples incubated at $37^{\circ} \mathrm{C}$ in a humidified atmosphere with $5 \% \mathrm{CO}_{2}$ for various periods of time $(3 \mathrm{~h}, 6 \mathrm{~h}, 24 \mathrm{~h}, 2$ days, 5 days and 14 days). The culture medium was changed every $24 \mathrm{~h}$. Polyethylene terephthalate coverslips (Thermanox ${ }^{\circledR}$,Nunc Inc., USA) were used as control sample.

\subsection{Cell culture characterization analysis}

Prior observing the cell morphology by SEM, the cell/support constructs were washed with DPBS (2-3 times) and then incubated with glutaraldehyde at $4^{\circ} \mathrm{C}$ for $1 \mathrm{~h}$ for cell fixation. The samples were then washed once again with DPBS (2 times) and dehydrated with a sequence of water/ethanol washes with increasing alcohol percentage. From $30 \%$ to $70 \%$ of ethanol, the samples were washed twice for 5 minutes each and from $70 \%$ to absolute ethanol the samples were washed once for 10 minutes each and finally left to dry at room temperature. Samples were gold coated, and observed with the JSM-5410 scanning electron microscope at an acceleration voltage of $10 \mathrm{kV}$.

Immunolabeling against vinculin antibody was used to recognize the focal adhesion on the electrospun membranes. Prior to immunostaining, the samples were fixed after $3 \mathrm{~h}, 6 \mathrm{~h}$ and $24 \mathrm{~h}$ of culture with formalin at $10 \%$ for $1 \mathrm{~h}$ and $4{ }^{\circ} \mathrm{C}$ and then washed three times in DPBS. The immunostaining was carried out following standard protocols [60]. Samples were incubated with the monoclonal vinculin antibody (dilution $1: 400$ ) in a $1 \%$ solution of bovine serum albumin (BSA) in DPBS at room temperature for $1 \mathrm{~h}$, followed by incubation for $1 \mathrm{~h}$ with the secondary antibody Alexa fluor 633-labeled anti-mouse $(5 \mu \mathrm{g} / \mathrm{ml})$ mixed with BODIPY® FL phallacidin $(10 \mu \mathrm{l} / \mathrm{sample})$ to label the actin cytoskeleton in $1 \% \mathrm{BSA} / \mathrm{DPBS}$ at room temperature. At last, the substrates were washed with $0.5 \%$ DPBS/Tween 20 and mounted adding a drop of VECTASHIELD® with incorporated 4',6-diamidino-2-phenylindole (DAPI, 
Vector Laboratories, Peterborough, UK). The samples were analyzed by confocal laser scanning microscopy (CLSM) Leica TCS SP2 AOBS (Germany).

The viability of pre-osteoblastic cells was determined using the MTS assay following the manufacturer's instructions. The assay is based on the mitochondrial activity of living cells. Three different times (2, 5 and 14 days) and four samples were analyzed for all the scaffolding cultured materials in order to obtain a better understanding of the evolution of cell viability on each scaffold. The absorbance at $490 \mathrm{~nm}$ was measured using a Perkin Elmer/ Wallac 1420 Multilaber Counter (USA). In order to visualize and be able to distinguish viable from dead cells, calcein was used to stain live cells with a green color and ethidium to mark the dead cells with a red color. To analyze the percentage of live and dead cells in the samples a CLSM was used with the aid of an incubator $\left(37^{\circ} \mathrm{C}\right.$ and $\left.5 \% \mathrm{CO}_{2}\right)$ for keeping the cells alive while capturing images.

\section{Results and discussion}

\subsection{Solution properties evaluation}

Table 2: Solution properties.

\begin{tabular}{cccccc}
\hline $\begin{array}{c}\text { Concentration } \\
\text { \%w/v }\end{array}$ & $\begin{array}{c}\text { Solvent ratio } \\
\text { \%DCM-DMF }\end{array}$ & $\begin{array}{c}\text { Density } \\
\left(\mathbf{k g} / \mathbf{m}^{\mathbf{3}}\right)\end{array}$ & $\begin{array}{c}\text { Conductivity } \\
(\mathrm{mS} / \mathrm{m})\end{array}$ & $\begin{array}{c}\text { Viscosity } \\
(\mathrm{mPa})\end{array}$ & $\begin{array}{c}\text { Surface } \\
\text { tension } \\
(\mathrm{mN} / \mathrm{m})\end{array}$ \\
\hline $\mathbf{1 0}$ & $80-20$ & 1250 & 0.020 & 24.6 & 31.5 \\
& $90-10$ & 1290 & 0.025 & 22.4 & 33.7 \\
$\mathbf{1 2}$ & $80-20$ & 1350 & 0.014 & 42.4 & 33.0 \\
& $90-10$ & 1360 & 0.015 & 40.0 & 34.3 \\
$\mathbf{1 5}$ & $80-20$ & 1360 & 0.005 & 76.0 & 33.5 \\
& $90-10$ & 1380 & 0.008 & 73.3 & 36.8 \\
\hline
\end{tabular}

The density, conductivity, viscosity and surface tension of the PCL solutions in different DCM/DMF mixtures are listed in Table 2 for the different polymer concentrations.

The density of the solution moderately increased with PCL content while the conductivity decreased. These parameters only slightly changed with DCM/DMF ratio. The density slightly increased with increasing DCM content, which can be explained by the higher density of DCM compared to DMF, and the conductivity also increased at least in this composition interval. Large discrepancies among the absolute values of the conductivity of PCL solutions in DCM/DMF mixtures can be found in the literature [45, 61-63] but they also report increases of the conductivity with larger DMF content. The different behavior found by the different authors must be ascribed to the different purity of the chemicals used in each work.

As the solution concentration increased, also did the viscosity. The value of the viscosity increased with the content of DMF in the solvent mixture for any polymer content; however, the differences were not significant. To this point, contradictory results can be found in the literature as well: Khil et al. have reported that viscosity decreased as DMF volume fraction increased [61]; Theron et al. have found that the viscosity increased as the DMF ratio increase [45]; Lee et al, have shown that the viscosity remained approximately constant for a $13 \mathrm{wt} \%$ PCL solution with DMF content between 0 and $25 \%$ [63]. 
The differences obtained in surface tension values were also not really significant. Nevertheless, a slight increase of surface tension with increasing PCL content can be observed. Also, the surface tension increased with DMF content in the solvent mixture. Again, contradictory results can be found in the literature: Lee et al. have found that the surface tension decreased when the DMF ratio increased [63], whereas other authors have reported an increasing of surface tension when increasing DMF content in the mixture [45, $61]$.

\subsection{Morphology of the electrospun mats}
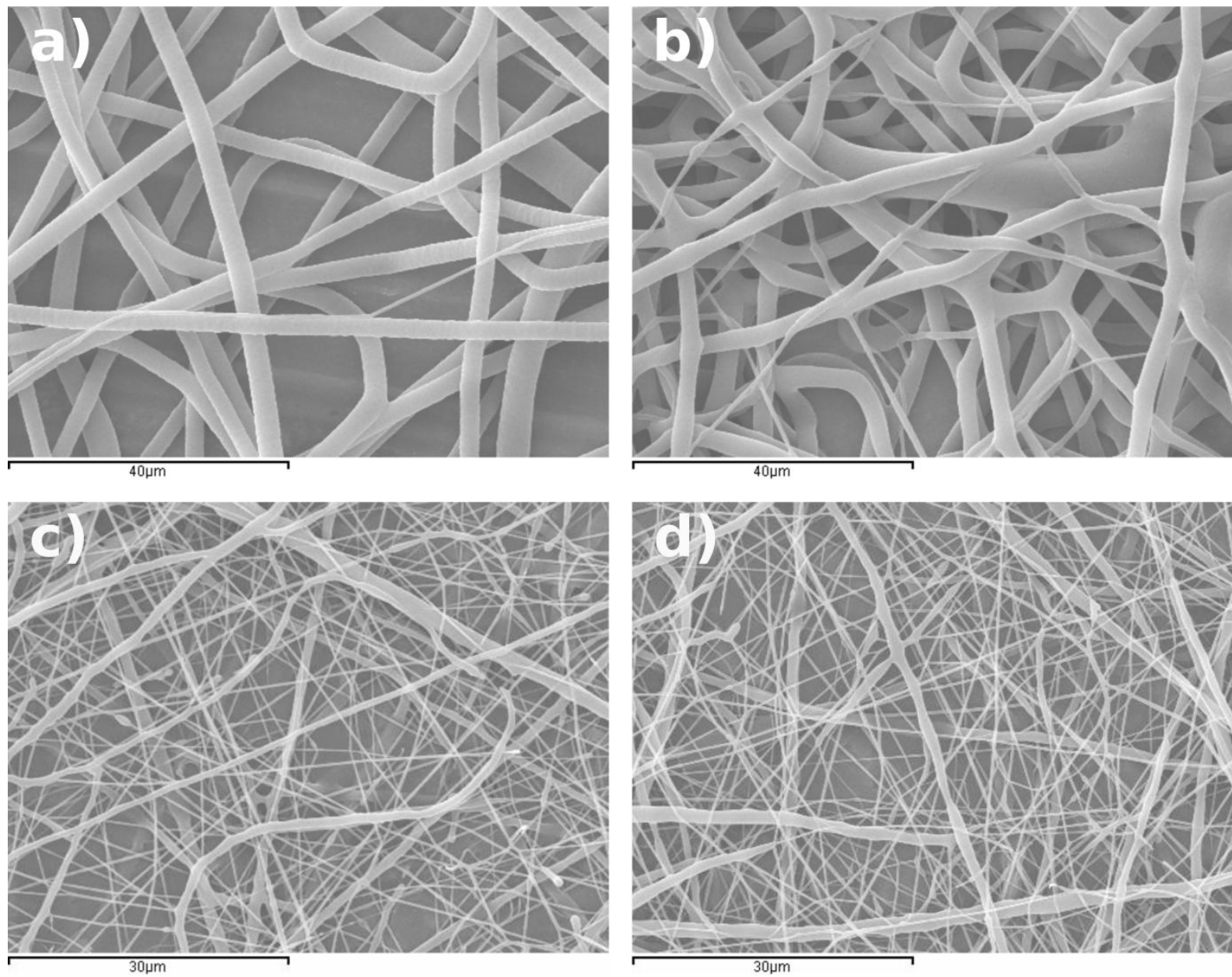

Figure 1: SEM images corresponding to four experiments of the $L_{18}$ array: (a) experiment 3, (b) experiment 6, (c) experiment 12 and (d) experiment 13 of table 1.

SEM images were used for analyzing the morphology of the electrospun mats. In Fig. 1 we have selected pictures corresponding to several experiments included in Table 1. The PCL mats obtained with the different processing conditions showed a mesh of randomly oriented fibers. The fiber diameter distribution and morphology depended very much on the processing parameters. In most of the experiments the presence of bimodal diameter distributions was quite apparent, as shown in Figs. 1b, c, and d. The presence of sub-structures of smaller fibers can be explained by the formation of a secondary jet during the main electrospinning procedure due to high solution viscosity. This bimodal structure is also related to certain 
process conditions, such as high voltage, low relative humidity and fast phase separation of polymer and solvent during the travel between the needle and the collector [64]. This was observed in all experiments except for experiments number 3, 4, and 8. See for instance Fig. 1a, corresponding to experiment 3 , in which a more homogeneous fiber diameter distribution was found with only one small diameter fiber in the image. According to the data of Table 1, it may be noticed that thicker fibers in the mats were obtained when performing experiments 3, 4 and 6. Experiments 10, 12 and 13 had the smallest diameters obtained in all the optimization study with values ranging between 0.54 and $0.81 \mu \mathrm{m}$. The rest of the experiments had results below $2.0 \mu \mathrm{m}$.

\subsection{Taguchi methodology analysis}

To determine the effect each variable had on the output, the average of fiber diameter and standard deviation found for the different levels of each parameter were calculated and are presented in Table 3. In this table the range is the difference between the maximum and the minimum values of the three levels, and importance of the parameter is obtained by the range, the one with the largest range being the most important [56]. 
Table 3: Mean effects of different levels of each parameter on fibre diameter and its SD. The importance of the parameter is determined by the range, the difference between the maximum and the minimum, of each parameter (largest range is the most important). The best level leading to the smallest diameters and the narrowest diameter distributions were also selected.

\begin{tabular}{clccccc}
\hline & & $\begin{array}{c}\text { Solvents ratio } \\
\text { (DCM-DMF) }\end{array}$ & $\begin{array}{c}\text { Applied } \\
\text { Voltage }\end{array}$ & Flow rate & $\begin{array}{c}\text { Solution } \\
\text { concentration }\end{array}$ & Gap distance \\
\hline \multirow{2}{*}{ Fibre } & Level 1 & 2.19 & 1.52 & 1.45 & 1.27 & 1.72 \\
diameter & Level 2 & 1.12 & 2.00 & 1.48 & 1.58 & 1.61 \\
$\bar{x}(\mu \mathrm{m})$ & Range 3 & 1.07 & 0.55 & 0.58 & 0.85 & 0.11 \\
& Importance & 1 & 4 & 3 & 2 & 5 \\
\hline \multirow{2}{*}{$\begin{array}{c}\text { Standard } \\
\text { deviation }\end{array}$} & Level 2 & 0.56 & 1.00 & 0.62 & 0.68 & 0.65 \\
\multirow{2}{*}{$(\mu \mathrm{m})$} & Level 3 & & 0.45 & 2.03 & 2.12 & 0.96 \\
& Range & 0.42 & 0.39 & 0.46 & 0.56 & 0.32 \\
& Importance & 3 & 4 & 2 & 1 & 5 \\
\hline Best level & & $80-20$ & $25 \mathrm{kV}$ & $3 \mathrm{ml} / \mathrm{h}$ & $10 \% \mathrm{w} / \mathrm{v}$ & $15 \mathrm{~cm}$ \\
\hline
\end{tabular}

From these results, we observe that DCM/DMF ratio and solution concentration had the biggest influence on the fiber diameter while the solution concentration and flow rate were the most influential on standard deviation. The effect of solvents ratio was quite clear, electrospinning a solution with the 80/20 DCM/DMF solvents ratio yielded the thinnest and most homogeneous fibers. The effect of concentration was also very clear; by increasing the polymer concentration in the solution, the fiber diameter and its standard deviation increased. It can also be noticed that by increasing the flow rate, the fiber diameter and standard deviation also increased. On the contrary, the effect of the applied voltage was not clear. It depended very much on the rest of parameters. Very similar results were obtained for 15 and $25 \mathrm{kV}$ while significant differences were found for $20 \mathrm{kV}$ the intermediate value of applied voltage. The effect of the applied voltage on fiber diameter is not clear in the literature; while in several cases a decrease of fiber diameter with increasing applied voltage has been reported [65-68] in other cases non-significant or non-monotonous changes were found [44, 69, 70]. The effect of travelling distance also was not very important; there were no significant differences between 15 and $20 \mathrm{~cm}$ gap distance, while showing a small decrease of fibers diameter from 10 to $15 \mathrm{~cm}$ and decreasing standard deviation, as well. Thus, we chose a 
DCM/DMF ratio 80-20, $10 \mathrm{wt} \%$ for the solution concentration, $3 \mathrm{~mL} / \mathrm{h}$ for the flow rate, 25 $\mathrm{kV}$ for the applied voltage and $15 \mathrm{~cm}$ for the nozzle-collector distance as the optimal values. In Fig. 2, we show SEM images of the fiber mats obtained with the mentioned parameter set at two magnifications. An inhomogeneous mat of thin fibers (similar to Fig 1c and d) with a diameter average of approximately $0.78 \mu \mathrm{m}$ and standard deviation of $0.44 \mu \mathrm{m}$ was obtained. No usual defects, like beads or drops, can be seen in the mats.
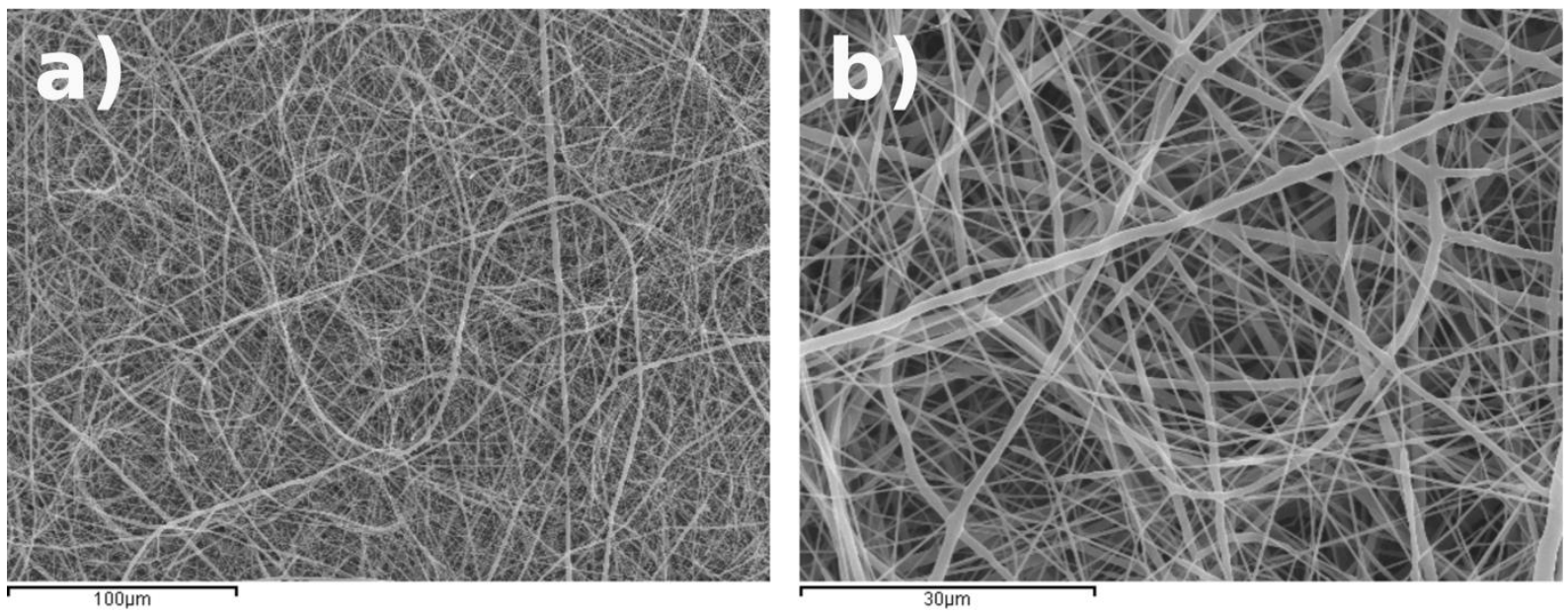

Figure 2: SEM images of thin fiber mats obtained with the operating conditions of $25 \mathrm{kV}$ as applied voltage; $15 \mathrm{~cm}$ as nozzle-collector distance; $3 \mathrm{~mL} / \mathrm{h}$ as feed rate; $10 \% \mathrm{w} / \mathrm{v}$ as polymer solution concentration and $80-20 \%$ as DCM-DMF ratio. Diameter average is approximately $0.78 \mu \mathrm{m}$ and standard deviation $0.44 \mu \mathrm{m}$.

Some experiments of the Taguchi array had lower diameter averages and standard deviations when compared to the results of the optimal experimental conditions. However, although these results, in number, appear better, when compared microscopically they lost to the optimized results because the mats had branched fibers, which are minor defects that can occur within the electrospinning performance, and also an irregular shape was visible on some fibers. In the optimal results the fibers are individual, there were no branches on the fibers and their shape was smooth and regular. They appear to be homogeneously deposited over each other without aggregation.

With Taguchi's methodology it was possible to produce a mat of thin fibers deposited homogeneously and very few defects, but also to understand which factors had the larger influences on the electrospinning process and how their variation affected the electrospun fibers and mats formation. In this particular study the most influential parameter was the solvents ratio. In order to confirm this feature, a series of experiments were performed in which the other parameters were set to their best levels (according to the Taguchi optimization methodology) while the most significant one was varied monotonously over a range larger than in the optimization experiment. The variation interval of the solvents ratio took into consideration the fact that contents of DCM below $70 \%$ yielded mats with the presence of beads and high non-homogeneity. Thus, Fig. 3 shows SEM images of electrospun mats made with PCL solutions in DCM/DMF with ratios 70/30, 90/10 and 100/0 by weight (the picture corresponding to the 80/20 ratio can be seen in Fig. 2). 

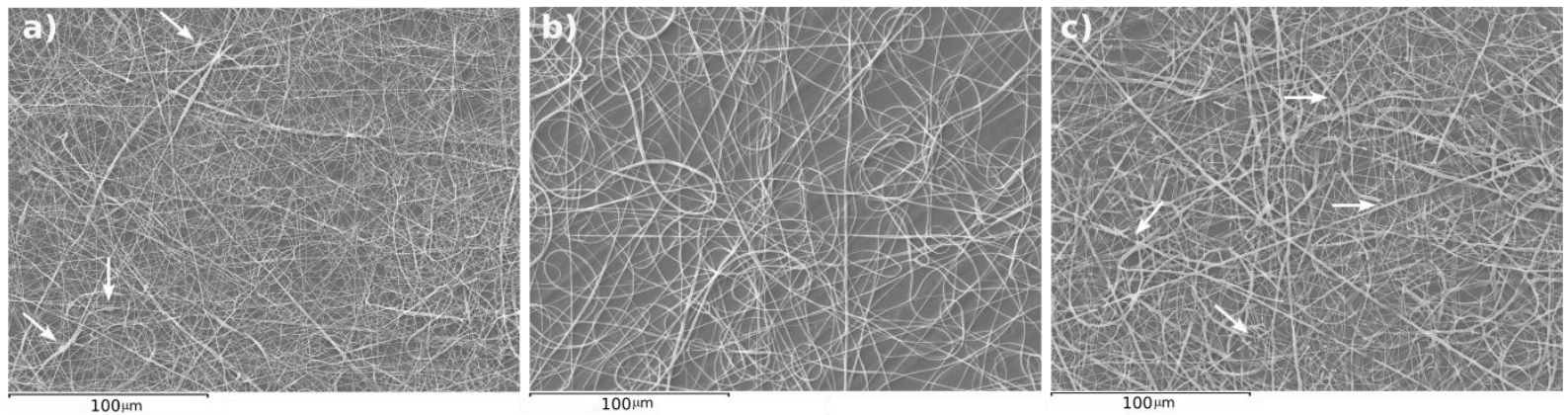

Figure 3: Solvents ratio effect on the electrospun fibers, 70-30\% (a), 90-10\% (b) and 100-0\% (c) as DCM-DMF\% ratio and $25 \mathrm{kV}$ as applied voltage; $15 \mathrm{~cm}$ as gap distance; $3 \mathrm{~mL} / \mathrm{h}$ as flow rate and $10 \% \mathrm{w} / \mathrm{v}$ as solution concentration. Scale bar $100 \mu \mathrm{m}$.

When increasing DCM content above $80 \%$, mainly when using only DCM, the diameter of the fibers increased and fibers become more irregular with some discontinuities and significant diameter changes along the fibers (see the arrows in Figure 3c). For $90 \%$ of DCM, we obtained a fiber diameter of $(0.81 \pm 0.31) \mu \mathrm{m}$ and $(0.89 \pm 0.40) \mu \mathrm{m}$ for pure DCM. Decreasing the DCM content below the ideal value, to $70-30 \%$ as solvent ratio, the fibrous structures were thinner and the diameter distribution was more homogeneous $(0.46 \pm 0.21 \mu \mathrm{m})$; however, imperfections across the mesh of fibers were common, with the presence of some beads (see arrows in Figure 3a).

\subsection{Morphology of the electrospun fibers incorporating nanoparticles}



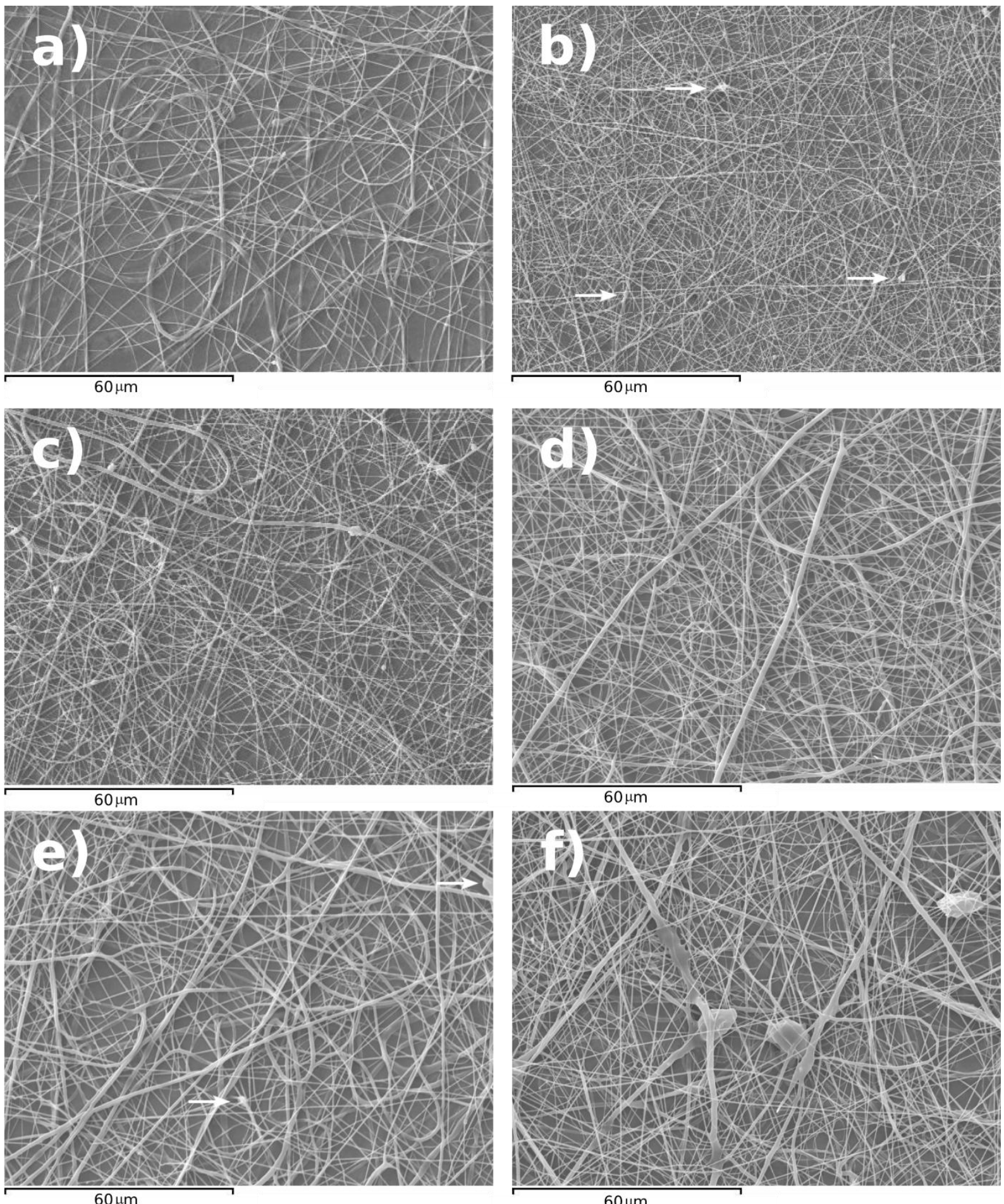

Figure 4. SEM images of mats incorporating (a) $1 \% \mathrm{HA}$; (b) $5 \% \mathrm{HA}$; (c) $10 \% \mathrm{HA}$; (d) $1 \%$ BG-NP; (e) $5 \%$ BG-NP and (f) $10 \%$ BG-NP.

Using the best processing parameters found for the PCL electrospinning, we produced electrospun nanocomposites incorporating nano-particles in the polymer solution. Fig. 4 shows the morphologic structure of the samples containing different percentages of hydroxyapatite (Figs. 4 a-c) and bioactive glass (Figs. 4 d-f) nano-particles in the polymer fibrous mats. 
The morphology of the electrospun nanocomposite changed slightly with respect to the pure PCL mats (Fig. 2). When incorporating 1\% of nano-particles a few small beads, possibly from the nano-particles, appeared along the fibers (Fig. 4a and d). Increasing the amount of nanoparticles to 5\%, agglomeration points were created (see the arrows in Figs. $4 \mathrm{~b}$ and e) and formation of larger beads that grew further when the filler content was increased to $10 \%$ (Figs. 4c and $\mathrm{f}$ ).

In addition, it is worth noting that when incorporating nano-particles the mean fiber diameter decreased monotonically compared to the values in the PCL mats, to the value of $0.3 \mu \mathrm{m}$ in the case of HA-NP, and to the value of $0.5 \mu \mathrm{m}$ for BG-NP (see data at the end of Table 1). The fiber diameter obtained was slightly larger than that of nanoparticles (the size of the HANPs was smaller than $200 \mu \mathrm{m}$ and in the case of BG-NPs ranged between 100nm and 800nm). The suspension of the nanoparticles in the PCL solution produced small changes in the conductivity and viscosity that can explain the small changes in the morphology of the fibrils.

\subsection{In-vitro bioactivity tests}
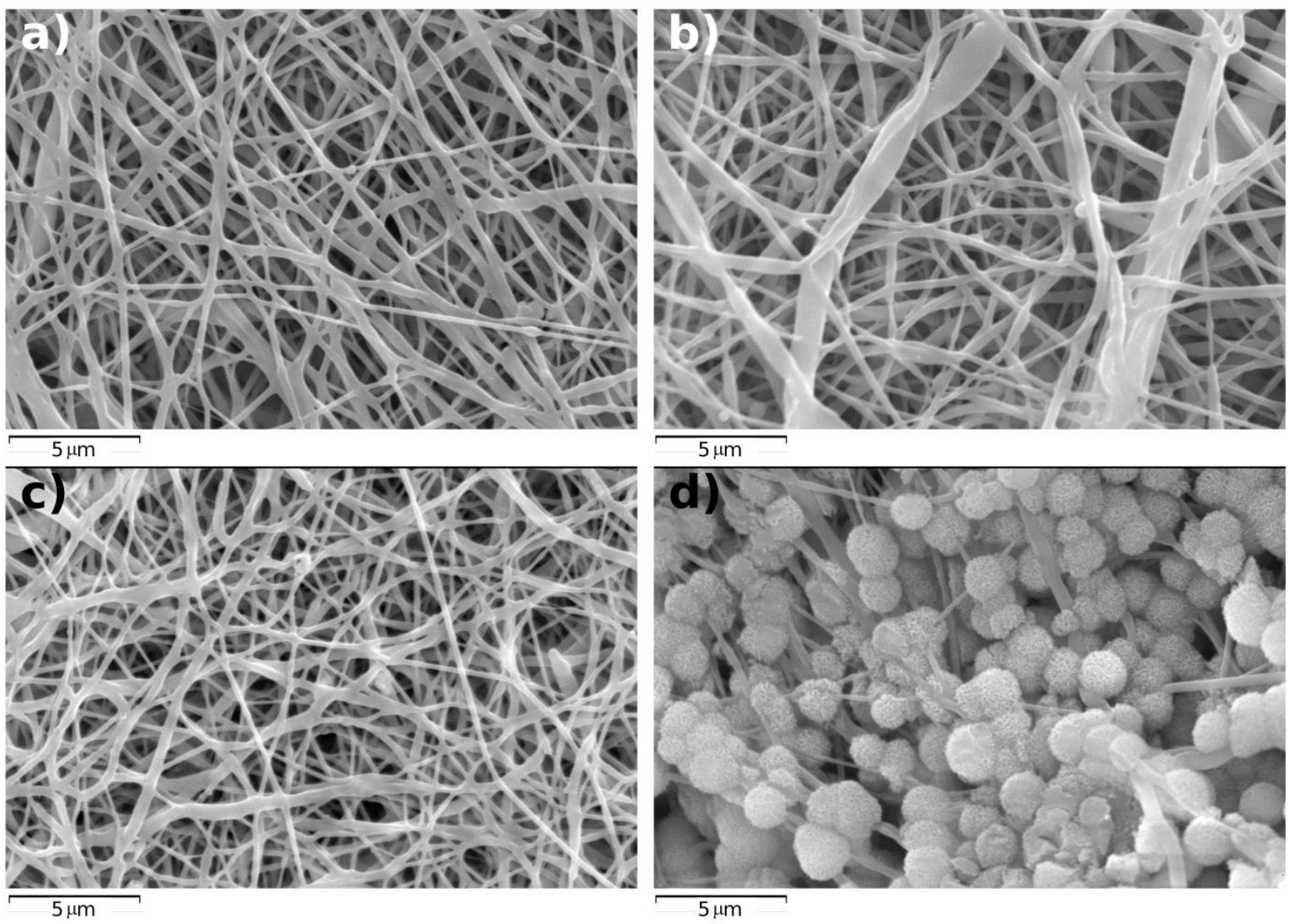

Figure 5: SEM images of some of the obtained optimized substrates after immersion in SBF for 7 days. a) Pure PCL membrane; b) PCL with 5\% BG-NP; c) PCL with 5\% HA; d) PCL with $10 \%$ HA.

The composite and pure PCL optimized membranes were immersed in SBF for 7 days to evaluate their capability to induce the precipitation of apatite in vitro, as is shown in the SEM images of Fig. 5. It is possible to conclude that the pure PCL substrate was not bioactive (Fig. $5 a)$. Even with the inclusion of either $5 \%$ of BG-NP or $5 \%$ of HA, no calcification could be 
detected. However, with the inclusion of $10 \%$ of HA a clear deposition of cauliflower-like structures, presumably of apatite, could be observed. This result demonstrates that bioactive nanocomposite membranes could be obtained using the proposed methodology. In nanocomposites with the smallest nanoparticle contents, the filler seems to be completely encapsulated in the polymer fibers, not appearing at the surfaces, and thus showing no initial effect on bioactivity since no polycaprolactone degradation takes place in the seven days of the test. Osteoconductive properties of the nanocomposite could possibly be manifested at longer implantation times with fibril erosion.

\subsection{Cell culture evaluation}
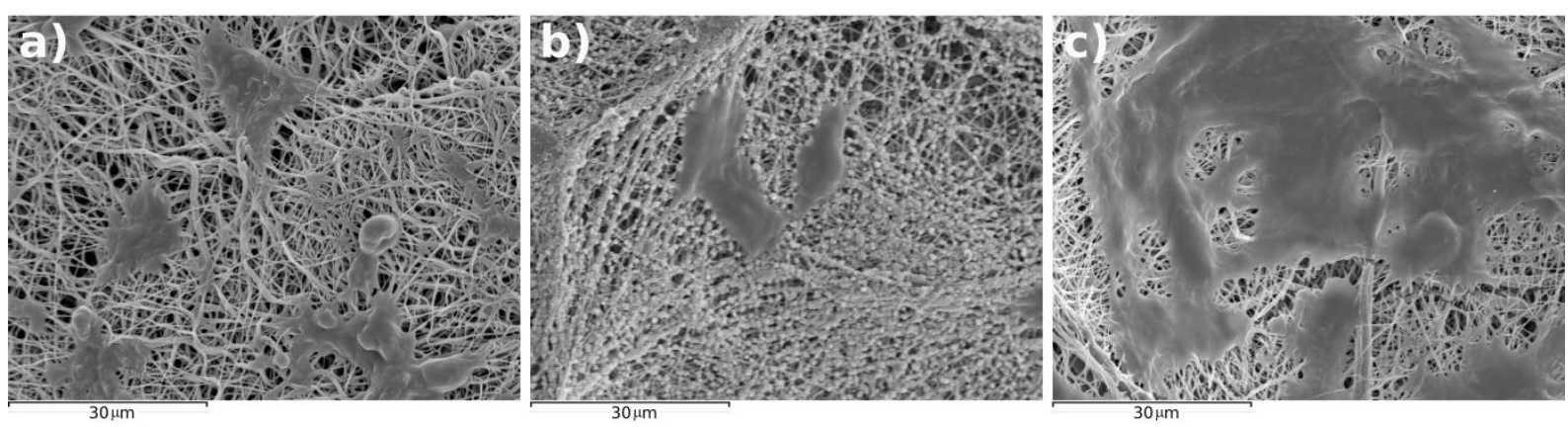

Figure 6. SEM images of pre-osteoblastic cells attached to the developed scaffolding materials after five days of culture: (a) PCL with 1\%HA; (b) PCL with 10\%HA and (c) PCL with $5 \%$ BG-NP.

The SEM images of Fig. 6 show that cells attach and spread on the electrospun membranes and acquired complex shapes due to the difficulty in finding adhesion points on the microfibrils of the substrate. This feature was confirmed by staining of the actin cytoskeleton shown in Fig. 8 (discussed below). 

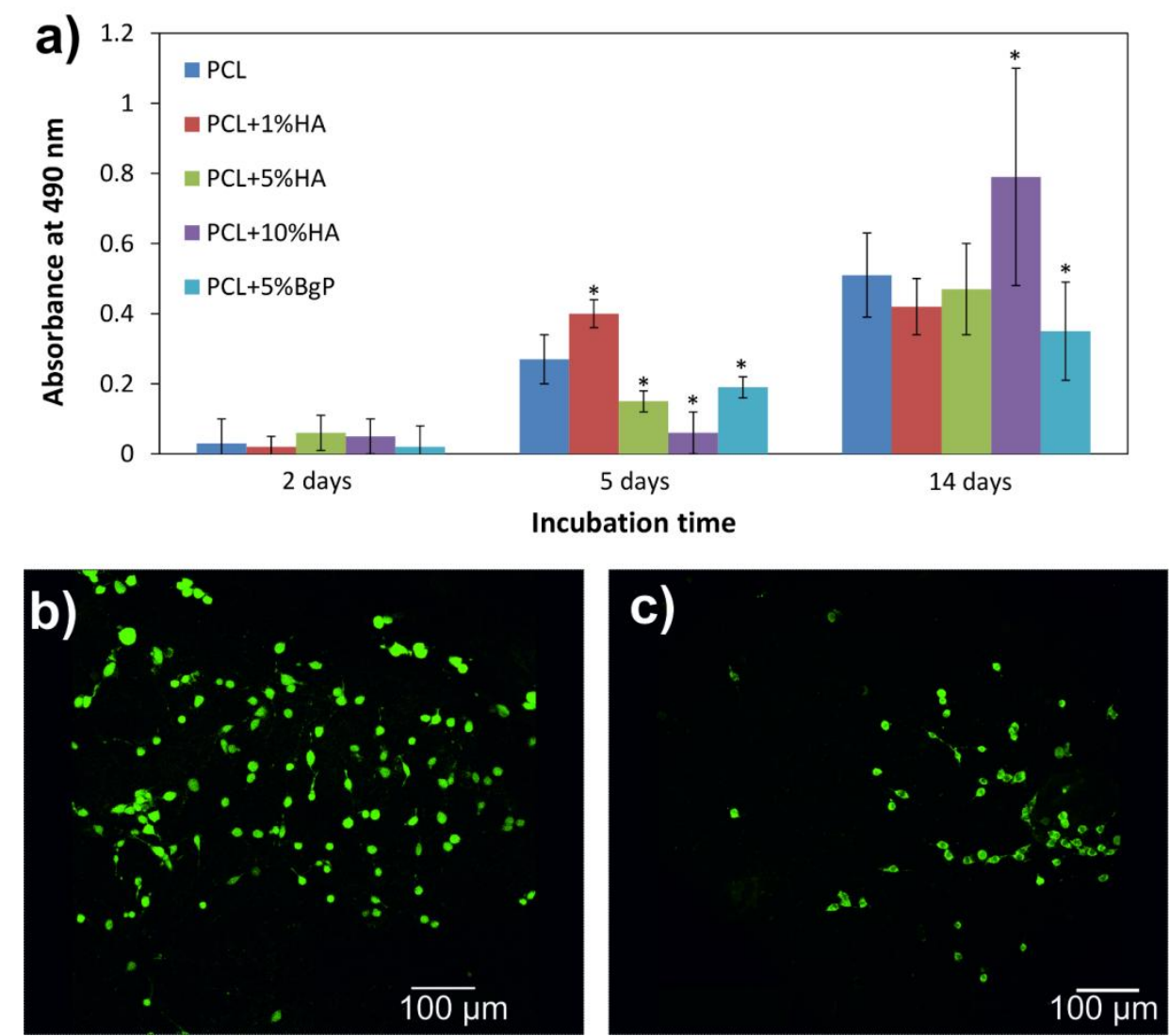

Figure 7. Cell viability on different electrospun membranes measured byMTS assay at 2, 5 and 14 days is shown in a). Viable (green) and dead (red) cells were stained after 5 days on pure PCL membranes b) and PCL+5\% HA c). Data show the average, standard deviation and its level of statistical significance using ANOVA test $(\mathrm{p}<0.05)$. The $*$ denotes significant differences between the composites and pure PCL membrane.

The results of the MTS analysis shown in Fig. 7a indicated that viable cells grew continuously with culture time on all the substrates but at different rates. In particular, the proliferation on the substrate with $1 \%$ HA-NP was very fast after 2 days, but at 14 days the cell viability was stabilized. After 14 days of culture no significant differences in cell viability were found among the nano-filled mats with $1 \% \mathrm{HA}$ and 5\%HA compared with pure PCL membrane. However, the electrospun membrane containing 10\% HA showed a marked proliferation with respect to the pure PCL mat. A similar behavior was obtained by Ródenas et al. [71] using PCL scaffolds with different content of HA. The membrane with BgP content show the lowest signal of viability after 14 days, however no significant differences were found between the membranes with the same content of particles of either $5 \% \mathrm{BgP}$ or $5 \% \mathrm{HA}$ in all the culture times evaluated. This result suggests that a higher concentration of bioglass is necessary to improve the cellular growth, as was reported by Hae-Hyoung et al. ref [72]. This can explain why the electrospun membrane containing 10\% HA showed a marked proliferation with respect to the pure PCL mat.

In order to confirm the cellular viability a live/dead cells assay was performed at 5 days of culture (see figure $7 \mathrm{~b}-\mathrm{c}$ ). These images further support the result obtained in the MTS assay, showing that cell proliferation was slower in the membranes containing nanoparticles although viability at the end of culture was even higher than in pure PCL. 

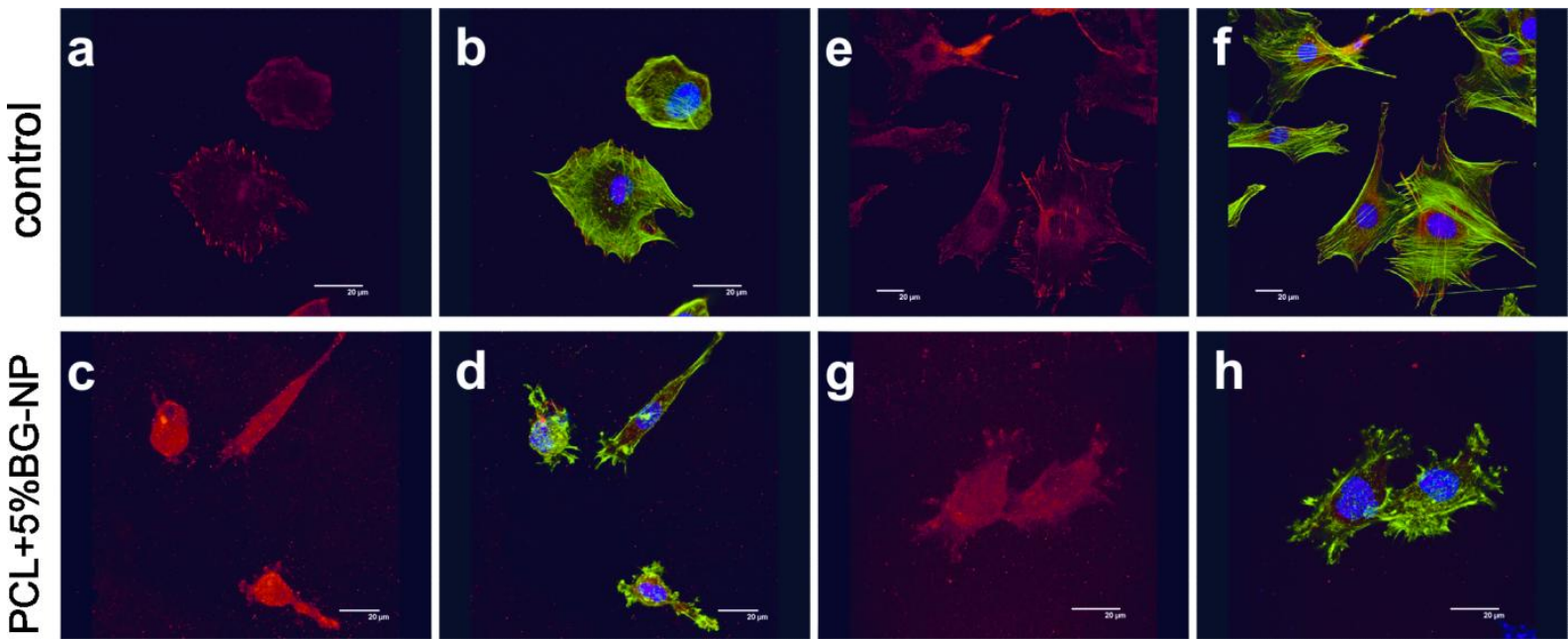

Figure 8. Immunostaining of vinculin and F-actin cytoskeleton label of in vitro cultures developed on a flat control and a PCL electrospun mat containing 5\% BG-NP for $3 \mathrm{~h}(\mathrm{a}-\mathrm{d})$ and $6 \mathrm{~h}(\mathrm{e}-\mathrm{h}), \mathrm{a}), \mathrm{c}), \mathrm{e})$ and g) show immunoflurescence images using anti-vinculin antibodies to prove focal adhesions. In (b), (d) f) and (h) the vinculin is colocalized with F-actin staining (green) while cell nuclei are counterstained in blue.

Cell attachment to the substrate starts by adsorption of proteins at the surface of the material, then the recognition of specific ligands in these proteins by transmembrane proteins, the integrins, that collect and cluster a series of proteins in cell cytoplasm (vinculin is a common focal adhesion protein) to form what is called a focal adhesion, actin cytoskeleton fibers polymerize from focal adhesions and reach the cell nucleus. The immunodetection of vinculin and F-actin cytoskeleton staining were indicative of cellular adhesion (see Figure 8). The morphology and adhesion behavior of the cells were similar when cultured on the different membranes. After $3 \mathrm{~h}$ culture on the flat control, perimetral focal adhesions were clearly, shown in Fig. 8a; the cells had an extended polygonal morphology with well defined contours and cytoskeleton. Perimetral focal adhesions colocalized with the ends of the F-actin fibers that densely filled the cytoplasm (see Figure 8b). However, a majority of the cells maintained a quite circular shape on the PCL/bioglass membranes: the labelling of vinculin (Fig. 8c) was diffuse with no marked focal adhesions and the actin cytoskeleton was mainly shown at the cell contour with incipient stress fibers, as shown in Fig. 8d. After $6 \mathrm{~h}$ culture, the cells were spread although the cell surface was much smaller compared with flat controls (Figure 8e-h). The adhesion points found on the membrane were localized on different fibrils and thus irregularly distributed. Some focal adhesions, labeled by intense vinculin spots at different points of the cell contour, were detected, although a diffuse expression was still shown (Fig. 8g) The distribution of the focal adhesions explains the irregular shape of the cells on the membranes shown in the SEM images of Fig. 6, as can also be observed by the stress fibers of the actin cytoskeleton (Fig. 8h).

\section{Conclusions}

Electrospinning of polycaprolactone dissolved in DCM/DMF mixtures was optimized by application of the Taguchi methodology with respect to five design parameters, two of them related to solution properties (solvents ratio and polymer concentration in the solution) and three more related to the process (applied voltage, travelling distance and flow rate). With the 
best set of parameters, mats consisting of uniform meshes of randomly distributed fibers were obtained. The mean diameter was $0.78 \mu \mathrm{m}$ with a standard deviation of $0.44 \mu \mathrm{m}$.

The DCM/DMF ratio was the most influential parameter on the mean fiber's diameter and morphology. The incorporation of increased ratio of DMF continuously decreased the fiber diameter but when its content in the solvents mixture was larger than $20 \%$ a significant number of imperfections in the fibers appeared.

Hydroxyapatite or bioactive glass nanoparticles can be successfully incorporated into the electrospun fibrils. Electrospinning of nanoparticle PCL suspensions yielded thinner fibrils than in the case of pure PCL when using the same processing parameters, probably due to changes in the physical properties of the solutions. Nanocomposite mats containing $10 \%$ by weight hydroxyapatite had higher bioactivity than pure PCL and mats containing less HA; however, when the amount of nanoparticles was smaller they were not exposed on the fibers surfaces. Use of smaller nano-filler contents would need fibers erosion when the scaffold is implanted. Biological response was studied by culturing MT3C3-E1 pre-osteoblasts on the sterilized mats. The viability results showed that the cells proliferated and were viable on all of the substrates with only small differences between them. The cell shape was quite irregular due to the random distribution of focal adhesions on the mats fibrils.

\section{Acknowledgments}

This work was supported by the Spanish Ministry of Science and Innovation through the MCINN-MAT2010-21611-C03-01 project. The authors also wish to thank the microscopy service of Universitat Politècnica de València as well as the confocal microscopy service of the Research Centre Principe Felipe for useful help and advice. 


\section{REFERENCES}

1. Prabhakaran, M.P.; Venugopal, J.; Ramakrishna, S. Electrospun nanostructured scaffolds for bone tissue engineering. Acta Biomater. 2009, 5, 2884-2893.

2. Kolambkar, Y.M.; Peister, A.; Ekaputra, A.K.; Hutmacher, D.W.; Guldberg, R.E. Colonization and Osteogenic Differentiation of Different Stem Cell Sources on Electrospun Nanofiber Meshes. Tissue Eng. Pt. A 2010, 16, 3219-3230.

3. Ruckh, T.T.; Kumar, K.; Kipper, M.J.; Popat, K.C. Osteogenic differentiation of bone marrow stromal cells on poly( $(\hat{I} \mu$-caprolactone) nanofiber scaffolds. Acta Biomater. 2010, 6 , 2949-2959.

4. Cai, Y.Z.; Wang, L.L.; Cai, H.X.; Qi, Y.Y.; Zou, X.H.; Ouyang, H.W. Electrospun nanofibrous matrix improves the regeneration of dense cortical bone. Electrospun nanofibrous matrix improves the regeneration of dense cortical bone 2010, 95A, 49-57.

5. Seyedjafari, E.; Soleimani, M.; Ghaemi, N.; Sarbolouki, M. Enhanced osteogenic differentiation of cord blood-derived unrestricted somatic stem cells on electrospun nanofibers. J. Mater. Sci.-Mater. M. 2011, 22, 165-174.

6. Wang, B.; Cai, Q.; Zhang, S.; Yang, X.; Deng, X. The effect of poly (L-lactic acid) nanofiber orientation on osteogenic responses of human osteoblast-like MG63 cells. J. Mech. Behav. Biomed. 2011, 4, 600-609.

7. Martins, A.; Alves da Silva, M.L.; Faria, S.; Marques, A.P.; Reis, R.L.; Neves, N.M. The Influence of Patterned Nanofiber Meshes on Human Mesenchymal Stem Cell Osteogenesis. Macromol. Biosci. 2011, 11, 978-987.

8. Chen, J.-P.; Chang, Y.-S. Preparation and characterization of composite nanofibers of polycaprolactone and nanohydroxyapatite for osteogenic differentiation of mesenchymal stem cells. Colloid. Surface. B 2011, 86, 169-175.

9. Patlolla, A.; Collins, G.; Arinzeh, T.L. Solvent-dependent properties of electrospun fibrous composites for bone tissue regeneration. Acta Biomater. 2010, 6, 90-101.

10. Garcia-Giralt, N.; Izquierdo, R.; Nogués, X.; Perez-Olmedilla, M.; Benito, P.; GómezRibelles, J.L.; Checa, M.A.; Suay, J.; Caceres, E.; Monllau, J.C. A porous PCL scaffold promotes the human chondrocytes redifferentiation and hyaline-specific extracellular matrix protein synthesis. A porous PCL scaffold promotes the human chondrocytes redifferentiation and hyaline-specific extracellular matrix protein synthesis 2008, 85A, 1082-1089.

11. Estellés, J.M.; Vidaurre, A.; Dueñas, J.M.M.; Cortázar, I.C. Physical characterization of polycaprolactone scaffolds. J. Mater. Sci.-Mater. M. 2008, 19, 189-195.

12. Causa, F.; Netti, P.A.; Ambrosio, L.; Ciapetti, G.; Baldini, N.; Pagani, S.; Martini, D.; Giunti, A. Poly-epsylon-caprolactone/hydroxyapatite composites for bone regeneration: In 
vitro characterization and human osteoblast response. J. Biomed. Mater. Res. A 2006, 76A, 151-162.

13. Mattanavee, W.; Suwantong, O.; Puthong, S.; Bunaprasert, T.; Hoven, V.P.; Supaphol, P. Immobilization of Biomolecules on the Surface of Electrospun Polycaprolactone Fibrous Scaffolds for Tissue Engineering. ACS Appl. Mater. Interfaces. 2009, 1, 1076-1085.

14. Han, J.; Branford-White, C.J.; Zhu, L.-M. Preparation of poly([epsilon]caprolactone)/poly(trimethylene carbonate) blend nanofibers by electrospinning. Carbohyd. Polym. 2010, 79, 214-218.

15. Marras, S.I.; Kladi, K.P.; Tsivintzelis, I.; Zuburtikudis, I.; Panayiotou, C. Biodegradable polymer nanocomposites: The role of nanoclays on the thermomechanical characteristics and the electrospun fibrous structure. Acta Biomater. 2008, 4, 756-765.

16. Dai, X.; Shivkumar, S. Electrospinning of hydroxyapatite fibrous mats. Mater. Lett. 2007, 61, 2735-2738.

17. Smith, L.A.; Ma, P.X. Nano-fibrous scaffolds for tissue engineering. Colloid. Surf. B 2004, 39, 125-131.

18. Woodruff, M.A.; Hutmacher, D.W. The return of a forgotten polymer-Polycaprolactone in the 21st century. Prog. Polym. Sci. 2010, 35, 1217-1256.

19. Barnes, C.P.; Sell, S.A.; Boland, E.D.; Simpson, D.G.; Bowlin, G.L. Nanofiber technology: Designing the next generation of tissue engineering scaffolds. Adv. Drug. Deliver. Rev. 2007, 59, 1413-1433.

20. Ducheyne, P.; Qiu, Q. Bioactive ceramics: the effect of surface reactivity on bone formation and bone cell function. Biomaterials 1999, 20, 2287-2303.

21. Boccaccini, A.R.; Erol, M.; Stark, W.J.; Mohn, D.; Hong, Z.; Mano, J.F. Polymer/bioactive glass nanocomposites for biomedical applications: A review. Compos. Sci. Technol. 2010, 70, 1764-1776.

22. Swetha, M.; Sahithi, K.; Moorthi, A.; Srinivasan, N.; Ramasamy, K.; Selvamurugan, N. Biocomposites containing natural polymers and hydroxyapatite for bone tissue engineering. Int. J. Biol. Macromol. 2010, 47, 1-4.

23. Wang, Y.; Zhang, S.; Zeng, X.; Ma, L.L.; Weng, W.; Yan, W.; Qian, M. Osteoblastic cell response on fluoridated hydroxyapatite coatings. Acta Biomater. 2007, 3, 191-197.

24. Shor, L.; Güçeri, S.; Wen, X.; Gandhi, M.; Sun, W. Fabrication of three-dimensional polycaprolactone/hydroxyapatite tissue scaffolds and osteoblast-scaffold interactions in vitro. Biomaterials 2007, 28, 5291-5297.

25. Wei, G.; Ma, P.X. Structure and properties of nano-hydroxyapatite/polymer composite scaffolds for bone tissue engineering. Biomaterials 2004, 25, 4749-4757. 
26. Rizzi, S.C.; Heath, D.J.; Coombes, A.G.A.; Bock, N.; Textor, M.; Downes, S. Biodegradable polymer/hydroxyapatite composites: Surface analysis and initial attachment of human osteoblasts. J. Biomed. Mater. Res. 2001, 55, 475-486.

27. Kim, H.M. Ceramic bioactivity and related biomimetic strategy. Curr. Opin. Solid. St. M. 2003, 7, 289-299.

28. Guo, H.; Su, J.; Wei, J.; Kong, H.; Liu, C. Biocompatibility and osteogenicity of degradable Ca-deficient hydroxyapatite scaffolds from calcium phosphate cement for bone tissue engineering. Acta Biomater. 2009, 5, 268-278.

29. Wang, Y.; Liu, L.; Guo, S. Characterization of biodegradable and cytocompatible nano-hydroxyapatite/polycaprolactone porous scaffolds in degradation in vitro. Polym. Degrad. Stabil. 2010, 95, 207-213.

30. Peter, M.; Binulal, N.S.; Soumya, S.; Nair, S.V.; Furuike, T.; Tamura, H.; Jayakumar, R. Nanocomposite scaffolds of bioactive glass ceramic nanoparticles disseminated chitosan matrix for tissue engineering applications. Carbohyd. Polym. 2010, 79, 284-289.

31. Chen, Q.Z.; Thompson, I.D.; Boccaccini, A.R. 45S5 Bioglasss-derived glass-ceramic scaffolds for bone tissue engineering. Biomaterials 2006, 27, 2414-2425.

32. Nirmala, R.; Nam, K.T.; Park, D.K.; Woo-il, B.; Navamathavan, R.; Kim, H.Y. Structural, thermal, mechanical and bioactivity evaluation of silver-loaded bovine bone hydroxyapatite grafted poly([epsilon]-caprolactone) nanofibers via electrospinning. Surf. Coat. Tech. 2010, 205, 174-181.

33. Mavis, B.; Demirtas, T.T.; Gümüsderelioglu, M.; Gündüz, G.; Çolak, Ü. Synthesis, characterization and osteoblastic activity of polycaprolactone nanofibers coated with biomimetic calcium phosphate. Acta Biomater. 2009, 5, 3098-3111.

34. Allo, B.A.; Rizkalla, A.S.; Mequanint, K. Synthesis and Electrospinning of ePolycaprolactone-Bioactive Glass Hybrid Biomaterials via a Sol-Gel Process. Langmuir 2010, $26,18340-18348$.

35. Jegal, S.-H.; Park, J.-H.; Kim, J.-H.; Kim, T.-H.; Shin, U.S.; Kim, T.-I.; Kim, H.-W. Functional composite nanofibers of poly(lactide-co-caprolactone) containing gelatin-apatite bone mimetic precipitate for bone regeneration. Acta Biomater. 2011, 7, 1609-1617.

36. Peng, F.; Yu, X.; Wei, M. In vitro cell performance on hydroxyapatite particles/poly(1lactic acid) nanofibrous scaffolds with an excellent particle along nanofiber orientation. Acta Biomater. 2011, 7, 2585-2592.

37. Ramakrishna, S.; Fujihara, K.; Teo, W.E.; Lim, T.C.; Ma, Z. An introduction to electrospinning and nanofibers; World Scientific, Singapore: 2005. 
38. Reneker, D.H.; Yarin, A.L. Electrospinning jets and polymer nanofibers. Polymer 2008, 49, 2387-2425.

39. Huang, Z.-M.; Zhang, Y.Z.; Kotaki, M.; Ramakrishna, S. A review on polymer nanofibers by electrospinning and their applications in nanocomposites. Compos. Sci. Technol. 2003, 63, 2223-2253.

40. Thompson, C.J.; Chase, G.G.; Yarin, A.L.; Reneker, D.H. Effects of parameters on nanofiber diameter determined from electrospinning model. Polymer 2007, 48, 6913-6922.

41. Wutticharoenmongkol, P.; Sanchavanakit, N.; Pavasant, P.; Supaphol, P. Novel Bone Scaffolds of Electrospun Polycaprolactone Fibers Filled with Nanoparticles. J. Nanosci. Nanotechno. 2006, 6, 514-522.

42. Cui, W.; Li, X.; Zhou, S.; Weng, J. Investigation on process parameters of electrospinning system through orthogonal experimental design. Investigation on process parameters of electrospinning system through orthogonal experimental design 2007, 103, 3105-3112.

43. Fong, H.; Chun, I.; Reneker, D.H. Beaded nanofibers formed during electrospinning. Polymer 1999, 40, 4585-4592.

44. Gómez-Tejedor, J.A.; Overberghe, N.V.; Rico, P.; Ribelles, J.L.G. Assessment of the parameters influencing the fiber characteristics of electrospun poly(ethyl methacrylate) membranes. Eur. Polym. J. 2011, 47, 119-129.

45. Theron, S.A.; Zussman, E.; Yarin, A.L. Experimental investigation of the governing parameters in the electrospinning of polymer solutions. Polymer 2004, 45, 2017-2030.

46. Heikkilä, P.; Harlin, A. Parameter study of electrospinning of polyamide-6. Eur. Polym. J. 2008, 44, 3067-3079.

47. Tehrani, A.H.; Zadhoush, A.; Karbasi, S.; Khorasani, S.N. Experimental investigation of the governing parameters in the electrospinning of poly(3-hydroxybutyrate) scaffolds: Structural characteristics of the pores. J Appl Polym Sci 2010, 118, 2682-2689.

48. Patra, S.; Easteal, A.; Bhattacharyya, D. Parametric study of manufacturing poly(lactic) acid nanofibrous mat by electrospinning. J. Mater. Sci. 2009, 44, 647-654.

49. Rosa, J.L.; Robin, A.; Silva, M.B.; Baldan, C.A.; Peres, M.P. Electrodeposition of copper on titanium wires: Taguchi experimental design approach. J. Mater. Process. Tech. 2009, 209, 1181-1188.

50. Taguchi, G.; Konishi, S. Taguchi Methods, Orthogonal Arrays and Linear Graphs; American Supplier Institute, Dearborn, MI, USA.: 1987. 
51. Maghsoodloo, S.; Ozdemir, G.; Jordan, V.; Huang, C.-H. Strengths and limitations of taguchi's contributions to quality, manufacturing, and process engineering. J. Manuf. Syst. 2004, 23, 73-126.

52. Areias, A.C.; Gómez-Tejedor, J.A.; Sencadas, V.; Alió, J.; Gómez Ribelles, J.L.; Lanceros-Mendez, S. Assesment of Parameters Influencing Fiber Characteristics of Chitosan Nanofibers Membrane in order to Optimize Fiber Mat Production. Polym. Eng. Sci. 2012, 52, 1293-1300.

53. Hong, Z.; Reis, R.L.; Mano, J.o.F. Preparation and in vitro characterization of scaffolds of poly(l-lactic acid) containing bioactive glass ceramic nanoparticles. Acta Biomater. 2008, 4, 1297-1306.

54. Hong, Z.; Reis, R.L.; Mano, J.F. Preparation and in vitro characterization of novel bioactive glass ceramic nanoparticles. J Biomed Mater Res 2009, 88A, 304-313.

55. Brown, M.; He, F.; Yeung, L., editors. The First International Symposium on optimization and Systems Biology (OSB’07); 2007; Beijing, China. ORSC \& APORC.

56. Taguchi, G. System of experimental design: engineering methods to optimize quality and minimize costs; White Plains, NY:UNIPUB: 1988.

57. Rekab, K.; Shaikh, M. Statistical design of experiments with engineering applications; CRC Press, Melbourne FL: 2005.

58. Wutticharoenmongkol, P.; Sanchavanakit, N.; Pavasant, P.; Supaphol, P. Preparation and Characterization of Novel Bone Scaffolds Based on Electrospun Polycaprolactone Fibers Filled with Nanoparticles. Macromol. Biosci. 2006, 6, 70-77.

59. Kokubo, T.; Takadama, H. How useful is SBF in predicting in vivo bone bioactivity? Biomaterials 2006, 27, 2907-2915.

60. Gamboa-Martinez, T.C.; Gomez Ribelles, J.L.; Gallego Ferrer, G. Fibrin coating on poly (L-lactide) scaffolds for tissue engineering. J Bioact Compat Pol 2011, 26, 464-477.

61. Khil, M.-S.; Bhattarai, S.R.; Kim, H.-Y.; Kim, S.-Z.; Lee, K.-H. Novel fabricated matrix via electrospinning for tissue engineering. J. Biomed. Mat. Res. B: Appl. Biomaterials 2005, 72B, 117-124.

62. Zamani, M.; Morshed, M.; Varshosaz, J.; Jannesari, M. Controlled release of metronidazole benzoate from poly [epsilon]-caprolactone electrospun nanofibers for periodontal diseases. Eur. J. Pharm. Biopharm. 2010, 75, 179-185.

63. Lee, K.H.; Kim, H.Y.; Khil, M.S.; Ra, Y.M.; Lee, D.R. Characterization of nanostructured poly([epsilon]-caprolactone) nonwoven mats via electrospinning. Polymer 2003, 44, 1287-1294. 
64. Ding, B.; Li, C.; Miyauchi, Y.; Kuwaki, O.; Shiratori, S. Formation of novel 2D polymer nanowebs via electrospinning. Nanotechnology 2006, 17, 3685-3691.

65. Demir, M.; Yilgor, I.; Yilgor, E.; Erman, B. Electrospinning of polyurethane fibers. Polymer 2002, 43, 3303-3309.

66. Megelski, S.; Stephens, J.; Chase, D.; Rabolt, J. Micro- and nanostructured surface morphology on electrospun polymer fibers. Macromolecules 2002, 35, 8456-8466.

67. Gao, K.; Hu, X.; Dai, C.; Yi, T. Crystal structures of electrospun PVDF membranes and its separator application for rechargeable lithium metal cells. Mater. Sci. Eng. B 2006, $131,100-105$.

68. Katti, D.; Robinson, K.; Ko, F.; Laurencin, C. Bioresorbable nanofiber-based systems for wound healing and drug delivery: optimization of fabrication parameters. J. Biomed. Mat. Res. B 2004, 70B, 286-296.

69. Zhao, S.; Wu, X.; Wang, L.; Huang, Y. Electrospinning of ethyl-cyanoethyl cellulose/tetrahydrofuran solutions. J Appl Polym Sci 2004, 91, 242-246.

70. Casper, C.; Stephens, J.; Tassi, N.; Chase, D.; Rabolt, J. Controlling surface morphology of electrospun polystyrene fibers: effect of humidity and molecular weight in the electrospinning process. Macromolecules 2004, 37, 573-578.

71. Ródenas-Rochina, J.; Ribelles, J.; Lebourg, M. Comparative study of PCL-HAp and PCL-bioglass composite scaffolds for bone tissue engineering. J. Mater. Sci: Mater. Med. 2013, 1-16.

72. Lee, H.H.; Yu, H.S.; Jang, J.H.; Kim, H.W. Bioactivity improvement of poly(epsiloncaprolactone) membrane with the addition of nanofibrous bioactive glass. Acta Biomater. $20084,622-629$. 